\title{
El derecho de retención en la Convención de Viena sobre compraventa internacional de mercaderías*
}

\section{Patricia leal Barros ${ }^{* *}$}

Resumen: A partir del estudio de la doctrina sobre el derecho de retención, se analiza la institución en el contexto de la Convención de Viena sobre Compraventa Internacional de Mercaderías. Partiendo de los requisitos que la doctrina ha considerado como insoslayables para el ejercicio del derecho de retención, se demuestra que esta institución se encuentra inmersa dentro de la Convención en dos supuestos, lo que permite inferir que el derecho de retención puede ser revalorizado como un nuevo remedio ante el incumplimiento en el Derecho Uniforme de los Contratos.

Palabras clave: Retención, derecho de retención, Convención de Viena, remedios.

\section{The Right of Retention in the Vienna Sales Convention of International Sales of Goods}

Abstract: From the study of the doctrine on the right of retention, the institution is analyzed in the context of the Vienna Convention on the International

* Fecha de recepción: I 7 de enero de 20I7. Fecha de aceptación: 2 de octubre de 20I7. Para citar el artículo: Leal Barros, P., "El derecho de retención en la Convención de Viena sobre compraventa internacional de mercaderías", Revista de Derecho Privado, Universidad Externado de Colombia, n. ${ }^{\circ}$ 33, julio-diciembre de 2017, I6I-192. DOI: https://doi.org/I0.18601/or234366.n33.07

** Abogada, Universidad del Zulia, Venezuela. Magíster en Derecho Mercantil, Universidad Dr. Rafael Belloso Chacín, Venezuela. Alumna regular del programa de Doctorado en Derecho, Universidad de los Andes, Santiago, Chile. Becaria de la Comisión Nacional de Investigación Científica y Tecnológica (Conicyt): Conicyt/Doctorado Nacional/2015-2 I 500 I 7 para estudios de Doctorado en Chile. Contacto: paleal@miuandes.cl 
Sale of Goods. Beginning with the requisites that the doctrine has considered as being unavoidable in order to practice the right of retention, we prove that this institution is immersed (included) within the Convention in two suppositions that allow inferring that the right of retention may be reassessed as a new recourse to face the non compliance of the Uniform Contracts Law.

Keywords: Retention, right of retention, Vienna Sales Convention, remedies.

\section{Introducción}

La Convención de Viena sobre compraventa internacional de mercaderías ${ }^{\mathrm{I}}$ ha venido cobrando importancia gradualmente desde su promulgación y consecuente acogida por el gran número de países que la suscribieron. El espléndido trabajo de unificación e interpretación de la tradición jurídica romana, conjuntamente con la tradición continental europea y el common law, ha sido sin duda lo que ha traído el éxito en la implementación de este cuerpo normativo en cuanto a la negociación internacional se refiere.

El análisis doctrinario de la Convención a través de los años, enriquecido con su aplicación por los diversos tribunales internacionales, ha dado pie a un cambio de paradigma en el derecho internacional privado al cual se le ha denominado Derecho Uniforme de los Contratos. La Convención es el principal exponente de esta doctrina, no solo por la gran cantidad de países que la acogieron, sino por la importancia de sus postulados, que han servido para replantear, estudiar y reinterpretar diversas instituciones del derecho, y en especial las acciones o derechos que tiene el acreedor frente al incumplimiento del contrato por parte del deudor. La Convención ha servido como un modelo para que los autores modernos hayan formulado la teoría de la pluralidad o batería de remedios que se despliegan para que, según sus propios requisitos, sean ejercidos por el acreedor.

Cabe conjeturar que el derecho de retención, vieja institución del derecho clásico de las obligaciones que hunde sus raíces en el derecho romano, puede ser recomprendido y, por ello, revalorizado a través de la teoría de los remedios contractuales del Derecho Uniforme. Como la Convención de Viena es el paradigma y crisol en el que se han ido forjando las modernas teorías, se daría un paso importante en la dirección anotada si pudiera identificarse que esta regulación del contrato de compraventa no solo reconoce el derecho de retención, sino que lo contempla como uno de los remedios de que dispone el acreedor (sea comprador o vendedor) para hacer frente a un incumplimiento.

Nuestra labor partirá con el estudio que la doctrina ha realizado sobre el derecho de retención, tomando en cuenta su configuración y los requisitos básicos

I Al hablar de la Convención de Viena sobre compraventa internacional de mercaderías nos referiremos a ella como la Convención de Viena, cISG, Viena o simplemente la Convención. 
para su ejercicio. Basándonos en esto, identificamos ciertos supuestos dentro de la Convención en los cuales se vislumbra el derecho de retención; estos son: la detención de las mercaderías por incumplimiento previsible del comprador, la conservación de las mercaderías y la retención de las estas, de los cuales determinamos los que corresponden a verdaderos supuestos de derecho de retención. Por último, configuramos el derecho de retención dentro de la Convención, identificando sus características, facultades, modos de extinción y su carácter de remedio, que forman parte del sistema que ofrece la Convención para paliar los efectos del incumplimiento.

\section{Retención simple y derecho de retención}

La retención implica tener la cosa de alguien, conservar, mantener una cosa. En muchos casos no implica el ánimo de devolución. Incluso hay quienes afirman que, para retener, simplemente es necesario un retenedor y una cosa retenida ${ }^{2}$. La retención, así vista, se encuentra en diferentes ramas del derecho, en el caso del derecho tributario está la retención de impuestos, está la retención por medida precautoria consagrada en el Código de Procedimiento Civil (art. 545 CPC chileno y art. 95 CPC colombiano). También se encuentra en el derecho laboral 3. Además de los diferentes supuestos de retención que contiene el Código Civil, en algunos de los cuales se encuentra inmerso el derecho de retención.

El derecho de retención, por su parte, es la facultad concedida por la ley al acreedor de conservar un bien del deudor, hasta el cumplimiento de la prestación pactada. Por tanto, constituye una medida de defensa del acreedor 4 . Si bien esta es la definición aportada por la mayoría de los autores ${ }^{5}$, parte de la doctrina afirma que no es suficiente para describir el supuesto legal del derecho de retención, el cual se refiere al crédito por los gastos hechos en o por la cosa retenida, o bien la indemnización de perjuicios por la mantención de la cosa retenida ${ }^{6}$.

2 Mateo y Villa, IÑigo, El derecho de retención, Cizur Menor (Navarra), Thomson Reuters Aranzadi, $2014,25$.

3 Existe la retención que puede realizar la empresa a la contratista por deudas de esta con sus trabajadores, en virtud del artículo I 83-C inciso segundo del Código del Trabajo incorporado por la Ley n. ${ }^{\circ} 20 .{ }_{2} 23$ en el caso del derecho chileno.

4 Ternera Barrios, Francisco y Mantilla Espinosa, Fabricio, "Posesión y retención: ¿hechos, derechos o quimeras?", Revista Chilena de Derecho Privado, Fundación Fernando Fueyo, diciembre 2010,125 .

5 Por todos, Claro Solar, Luis, Explicaciones..., cit., 496.

6 Díez-Picazo, Luis, Fundamentos de derecho civil patrimonial, t. II: Las relaciones obligatorias, $6 .{ }^{\text {a }}$ ed., Cizur Menor (Navarra), Thomson Civitas, 2008, 473. 


\section{A. Configuración del derecho de retención}

El derecho de retención es una medida de defensa que detenta el acreedor contra el deudor incumplidor, por la cual el acreedor se rehúsa a la entrega de un bien del deudor o al que se le debe su entrega, hasta tanto aquel no cumpla con la prestación a la que se obligó. Es un derecho, por cuanto el legislador le otorga esta prerrogativa al acreedor, que debiendo entregar la cosa la retiene como "garantía" de un futuro cumplimiento del deudor. Para su configuración es necesaria la existencia de ciertos requisitos que ha configurado la doctrina.

El derecho de retención se genera por la existencia de un crédito impago por parte del deudor y la tenencia lícita de una cosa por parte del acreedor. Requiere, entonces, que previamente exista un crédito, por lo que no puede considerarse una institución autónoma7. El derecho de retención es, por tanto, accesorio, hace falta la existencia de un incumplimiento para que el acreedor tenga derecho a retener un bien del deudor.

La configuración del derecho de retención tal y como la vemos ahora con sus requisitos y supuestos básicos nos viene del Code francés ${ }^{8}$. Desde entonces ha tenido un tímido avance dentro de la doctrina. Hasta hoy se debate sobre su naturaleza jurídica -personal o real- o su carácter de principio general o de excepción.

En lo que sí hay acuerdo es que el derecho de retención deviene del principio de equidad natural9, porque se le otorga una garantía al acreedor de guardar un bien del deudor hasta tanto este no cumpla con la prestación. De lo contrario, es decir, obligar al acreedor a devolver la cosa del deudor sin que este haya cumplido su parte, sería exponerlo a una situación de riesgo y dejar al deudor en una posición de ventaja injusta.

\section{B. Requisitos del derecho de retención}

La doctrina ha ido configurando una serie de requisitos para la aplicación del derecho de retención. Nos centraremos en los que consideramos más importantes.

7 Sancho Rebullida, Francisco de Asís, "Facultad de retención posesoria". En Francisco de Asís Sancho Rebullida, Estudios de Derecho Civil I, Pamplona, Ediciones Universidad de Navarra, I 978, 252; Baraona González, Jorge, El retraso en el cumplimiento de las obligaciones, Madrid, Dykinson, I998, 3 I 8 .

8 Planiol, Marcel y Ripert, Georges, Tratado Elemental de Derecho Civil, t. vi: Contratos de garantía, privilegios e hipotecas, José M. Cajica (trad.), México, Cárdenas Editor y Distribuidor, I 99i, 84; Mateo y Villa, IÑigo, El derecho de retención..., cit., 59; Cano, J. Ignacio, La retención de cosa ajena, Barcelona, Bosch, I990, I3.

9 Giongi, Jorge. Teoría de las Obligaciones en el derecho moderno, vol. II, Madrid, Imprenta de la Revista de Legislación, I909, 430; Díez-Picazo, Luis, Fundamentos de derecho civil patrimonial..., cit., 476. 


\section{De carácter legal}

Es un derecho establecido por ley. Existen en doctrina dos posiciones contrapuestas sobre este aspecto: por un lado, están los que afirman que la legalidad es una característica medular del derecho de retención ${ }^{\mathrm{IO}}$, porque la legislación establece de forma precisa los casos en que se puede activar esta facultad. Y por el otro lado están los que defienden la idea de que la ley establece un principio general que permite aplicar el derecho de retención en cualquier caso en que se presenten los requisitos ${ }^{\mathrm{I}}$. Nos decantamos por la primera de las posturas, porque se trata de un medio de autotutela consagrado por el legislador y como tal solamente se puede ejercer en los supuestos debidamente indicados por la norma. Por tanto, el incumplimiento que es necesario para aplicar el derecho de retención no sería cualquier incumplimiento, sino aquellos prefijados por la norma como supuestos de hecho.

\section{Tenencia legítima de una cosa}

Por regla general, la cosa debe estar en manos de quien pretende invocar el derecho $^{\mathrm{I2}}$. La doctrina ha discutido sin acordar si se trata de posesión natural ${ }^{13}$ del bien o simple detención de este ${ }^{\mathrm{I}}$. Lo cierto es que quien quiera hacer valer el

IO Entre los seguidores de esta postura se encuentran Claro Solar, Luis, Explicaciones..., cit., 496; Albaladejo, Manuel, Derecho Civil, ir: Derecho de Obligaciones, vol. i: La obligación y el contrato en general, Barcelona, José María Bosch, i 997, 248; Díez- Picazo, Luis y Gullón, Antonio, Instituciones de Derecho Civil, vol. i, Madrid, Tecnos, i 995, 5 I 2; Pérez Álvarez, Miguel Ángel, "La protección del crédito". En Carlos Martínez de Aguirre Aldaz (coord.), Curso de Derecho Civil, vol. II, 4. ${ }^{\text {a }}$ ed., Colex, 20 I4, 2 9; Galgano, Francesco, Trattato di Diritto Civile, vol. III, 2. ${ }^{\text {a }}$ ed., Casa Editrice Dott. Antonio Milani, 20 o, 367-368; Echevarría de Rada, Teresa, "En torno al derecho de retención”. En Antonio Cabanillas Sánchez et al. (orgs.), Estudios jurídicos en homenaje al profesor Luis Díez-Picazo, t. II: Derecho Civil. Derecho de Obligaciones, Madrid, Thomson Civitas, 2003, I767; Díez-Picazo, Luis, Fundamentos de derecho civil patrimonial..., cit., 476. El Código Civil chileno (art. 2392) y el colombiano (art. 24I7) acogen esta postura.

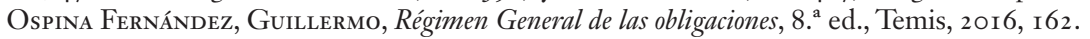

i I Dentro de esta corriente, Giorgi, Jorge, Teoría..., cit., 430; López de Haro, Carlos, El derecho de retención, Madrid, Reus, i92 I, io y 60; Abeliuk Manasevich, René, Las Obligaciones, t. II, 6 . $^{\text {a }}$ ed., Legal Publishing Thomson Reuters, 20 I4, i I 25 ; Pizarro Wilson, Carlos, "El derecho de

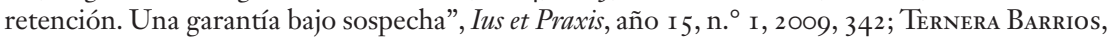
Francisco y Mantilla Espinosa, Fabricio, "Posesión y retención: ¿hechos, derechos o quimeras?”, Revista Chilena de Derecho Privado, Fundación Fernando Fueyo, diciembre 2010, I 29.

i 2 López de Haro, Carlos, El derecho de retención..., cit., 7; Claro Solar, Luis, Explicaciones..., cit., 496; Abeliuk Manasevich, René, Las Obligaciones..., cit., i i 26 ; Fueyo Laneri, Fernando, Cumplimiento e incumplimiento de las obligaciones, Santiago, Editorial Jurídica de Chile, I99 I, 522 ; Albaladejo, Manuel, Derecho Civil..., cit., 244; Sancho Rebullida, Francisco de Asís, "Facultad de retención posesoria”. En Francisco de Asís Sancho Rebullida, Estudios de Derecho Civil I, Pamplona, Ediciones Universidad de Navarra, I978, 252.

I 3 Cuando en este trabajo se hable de posesión, se entenderá como posesión natural o mera tenencia del bien sin ánimo de dueño.

i4 Mateo y Villa, IÑigo, El derecho de retención..., cit., I23-I3 I. 
derecho de retención debe tener la cosa bajo su control. Si pierde la tenencia de la cosa, ya no podrá hacer valer el derecho ${ }^{15}$. La tenencia del bien también debe estar libre de vicios, debe ser legítima. El acreedor no puede haber obtenido el bien valiéndose de la violencia o la clandestinidad ${ }^{\mathrm{i}}$.

La cosa retenida debe ser ajena, mueble o inmueble, comercializable e infungible $^{17}$. Aunque tradicionalmente se ha dicho que debe tratarse de cosas corporales $^{18}$, algunas legislaciones permiten la retención de valores de crédito, incluso se ha hablado de retener datos informáticos ${ }^{19}$. La tenencia también puede ser ejercida por un tercero a nombre del retenedor ${ }^{20}$.

\section{Crédito cierto, líquido y exigible}

Para ejercer el derecho de retención debe existir un crédito cierto. En este sentido, no puede considerarse una institución autónoma, sino accesoria o subordinada a la existencia de un crédito $^{2 \mathrm{I}}$. La doctrina discute si el crédito debe o no ser líquido y exigible, es decir, vencido. Nos plegamos a lo establecido por la doctrina clásica que considera como un requisito del derecho de retención que el crédito de que se trate sea líquido y exigible ${ }^{22}$.

\section{Conexión entre el crédito y la cosa, o bien su tenencia}

Para que proceda el derecho de retención, debe existir alguna conexión entre la cosa retenida y el crédito. Existen en doctrina dos posiciones sobre la conexión: por un lado, la posición amplia admite cualquier conexión entre la cosa retenida

i 5 López de Haro, Carlos, El derecho de retención, cit., i3; Claro Solar, Luis. Explicaciones..., cit., 496; Abeliuk Manasevich, René, Las obligaciones..., cit., i i 26; Pizarro Wilson, Carlos, El derecho..., cit., 346; Galgano, Francesco. Trattato di Diritto Civile..., cit., 369; Díez-Picazo, Luis y Antonio Gullón, Instituciones de Derecho Civil..., cit., 5 I 3.

i6 Claro Solar, Luis, Explicaciones..., cit., 496, Abeliuk Manasevich, René, Las obligaciones..., cit., i 2 6; Ospina Fernández, Guillermo, Régimen General de las obligaciones..., cit., i65.

i Sancho Rebullida, Francisco de Asís, "Facultad de retención posesoria...", cit., 252 ; Abeliuk Manasevich, René, Las Obligaciones..., cit., i I 29.

i 8 Giongi, Jorge. Teoría..., cit., 423.

i9 Mateo y Villa, IÑigo. El derecho de retención..., cit., I 33.

20 Ya en el derecho romano se contemplaba la retención ejercida a manos de un tercero: D. 4I, 3, 33, 4; D’Ors, J. A., Derecho Privado Romano, Pamplona, Ediciones Universidad de Navarra, i989, i 94; Giorgi, Jorge, Teoría..., cit., 423.

2 I SAncho Rebullida, Francisco de Asís, "Facultad de retención posesoria...”, cit., 252 ; Baraona González, Jorge, El retraso en el cumplimiento de las obligaciones, Madrid, Dykinson, i 998, 3 I 8.

22 Claro Solar, Luis. Explicaciones..., cit., 497-498; Giorgi, Jorge, Teoría..., cit., 426-428, 432; Díez- Picazo, Luis y Antonio Gullón. Instituciones de Derecho Civil..., cit., 5i 2; Sancho Rebullida, Francisco de Asís, "Facultad posesoria...", cit., 252; Echevarría de Rada, Teresa, "En torno al derecho...", cit., i 776. Abeliuk Manasevich, René, Las obligaciones..., cit., i I 27 ; Ospina Fernández, Guillermo, Régimen General de las obligaciones..., cit., i 66. 
y el crédito, o bien su tenencia ${ }^{23}$, y por el otro lado la posición estricta establece que la conexión debe generarse a partir del crédito por los gastos incurridos en favor de la cosa o a razón de esta durante la retención, o bien la indemnización de perjuicios por la mantención de la cosa retenida ${ }^{24}$.

\section{El derecho de retención como "remedio contractual"}

El derecho de retención surge por el incumplimiento de una obligación. Entendido desde la mirada del nuevo Derecho de Contratos ${ }^{25}$, en donde el incumplimiento se caracteriza por su amplitud y por su naturaleza neutra desde el punto de vista de la imputación subjetiva al deudor. Este concepto de incumplimiento se construye tomando en cuenta la insatisfacción del interés del acreedor, configurado y garantizado por el contrato. El incumplimiento se refiere no solo a deberes de conducta del deudor, también puede tener como contenido determinados estados o situaciones de la realidad presupuestos en el contrato ${ }^{26}$.

Las partes se obligan a cumplir un todo; en otras palabras, no se obligan a cumplir una enumeración de obligaciones aisladas o fraccionadas, sino toda actividad que razonablemente se pueda esperar de ellas en el marco de un contrato voluntariamente aceptado ${ }^{27}$, todo atendiendo a un fin: la conservación del contrato $^{28}$. En caso de incumplimiento, se trata, pues, de un incumplimiento del contrato, no de la obligación ${ }^{29}$.

23 Mateo y Villa, Í̃̃igo, El derecho de retención..., cit., I 38 -I43, expone en su obra una visión detallada de las diversas opiniones en doctrina sobre la conexión y los tipos de conexión en el derecho de retención.

24 Díez-Picazo, Luis, Fundamentos de derecho civil patrimonial..., cit., 474.

25 Para ahondar en los orígenes del nuevo Derecho de Contratos, consultar: Morales Moreno, Antonio Manuel, La modernización del derecho de obligaciones, Cizur Menor (Navarra), Thomson Civitas, 2006, 25-29.

26 Morales Moreno, Antonio Manuel, "Claves de la modernización del derecho de contratos", en Iñigo De la Maza Gazmuri, Antonio Manuel Morales Moreno y Álvaro Vidal Olivares, Estudios de Derecho de Contratos. Formación, cumplimiento e incumplimiento, Santiago de Chile, Legal Publishing, 2or 4, 86; Morales Moreno, Antonio Manuel, "Conformidad de las mercaderías y pretensiones de terceros", en Luis Díez-Picazo y Ponce de León, La compraventa internacional de mercaderías. Comentario de la Convención de Viena, Cizur Menor (Navarra), Thomson Civitas, I997, 29 I.

27 Morales Moreno, Antonio Manuel, "Claves de la modernización...”, cit., 87; Vidal OlivaREs, Álvaro, "El incumplimiento contractual y los remedios de que dispone el acreedor en la compraventa internacional", Revista Chilena de Derecho, vol. 33, n. ${ }^{\circ}$, 2006, 449.

28 Sobre este punto: Oviedo Albán, Jorge, "Los principios generales en la Convención de Naciones Unidas sobre compraventa internacional de mercaderías", Boletín Mexicano de Derecho Comparado, vol. 47, n. ${ }^{\circ}$ I4I, 2014 , IO I 2 ; Vidal Olivares, Álvaro, El incumplimiento contractual y los remedios..., cit., 453 .

29 Morales Moreno, Antonio Manuel, La modernización..., cit., 30. 
La responsabilidad por incumplimiento se presenta entonces como un reparto de riesgos ${ }^{3 \circ}$, donde tanto acreedor como deudor deben asumir una parte de estos riesgos. A diferencia del derecho continental, toda la responsabilidad no recae en la parte que ha incumplido, sino también en la parte que pese a que ha cumplido con todas sus obligaciones debe mantener una conducta que aminore el riesgo y los gastos por el incumplimiento del otro ${ }^{3 \mathrm{I}}$. El incumplimiento, entendido de este modo, permite la unificación del sistema de responsabilidad contractual, desapareciendo la diversificación de supuestos inmersa en los códigos civiles para la distinción entre el incumplimiento y las garantías o saneamientos, como sistemas de responsabilidad diferentes ${ }^{32}$.

El nuevo Derecho de contratos articula un sistema de "remedios" 33 que puede utilizar el acreedor insatisfecho por el incumplimiento del contrato. Los remedios son medidas de protección que el ordenamiento jurídico ofrece al acreedor en caso de incumplimiento de la contraparte para obtener la mejor realización de su interés 34 . Los remedios pueden consistir en pretensiones otorgando la facultad de exigir al deudor un dar, hacer, o no hacer. También pueden ser derechos potestativos que facultan al acreedor para modificar, por medio de su sola voluntad, una situación jurídica35.

En ambos casos es necesario que concurra un supuesto de hecho específico, conformando un sistema articulado tanto para la protección del acreedor como para el reparto del riesgo ${ }^{36}$. Pero, si bien todos los remedios tienen como supuesto básico el incumplimiento, no todos exigen los mismos requisitos ${ }^{37}$.

Morales Moreno, Antonio Manuel, La modernización..., cit., 30; Vidal Olivares, Álvaro, El incumplimiento contractual y los remedios..., cit., 450.

3I Saidov, DJaknongir, The Law of damages in international sales. The CISG and other International Instruments, Oxford, Hart Publishing, 2008, I3 I.

Morales Moreno, Antonio Manuel, La modernización..., cit., 3 .

33 La palabra "remedios" es entendida en este trabajo desde su significado en inglés remedies, esto es, alternativas o soluciones al incumplimiento para la satisfacción de la prestación; FARNSWORтH, E. Allan, "Legal Remedies for Breach of Contract", Columbia Law Review, vol. 70, n. ${ }^{\circ} 7$, nov. I 970, I I 45-I 2 I6; Bray, Samuel L., "Announcing remedies", Cornell Law Review, vol. 97 , n. ${ }^{\circ}$ I I-I 7, 20I 2, 754-755. El término se ha castellanizado y es entendido como los "efectos anormales de la obligación"; en otras palabras, las medidas que puede ocupar el acreedor en caso de incumplimiento. Debido a la gran influencia del commom law en la redacción de la Convención de Viena, se ha incluido el término dentro de su articulado y en consecuencia se ha traducido literalmente al español en diversos estudios como los de Morales Moreno, Antonio Manuel, La modernización..., cit., 3o; Vidal Olivares, Álvaro, El incumplimiento contractual y los remedios..., cit., 452; Contardo GonzÁlez, Juan Ignacio, Indemnización y resolución por incumplimiento, Santiago, Thomson Reuters, 2015, I4, entre otros.

Morales Moreno, Antonio Manuel, "Claves de la modernización...”, cit., 93; Vidal OlivaREs, ÁlVARo, El incumplimiento contractual y los remedios..., cit., $45^{2}$.

Morales Moreno, Antonio Manuel. La modernización..., cit., 30-3 I. 
En el caso del derecho de retención existe el incumplimiento de un crédito, que da lugar a que quien deba entregar una cosa del deudor la retenga hasta que vea satisfecha su pretensión. Esto ubica al derecho de retención como un remedio contractual. Porque cumple con el requisito básico, el incumplimiento, y contiene además otro propio, el retener un bien hasta ver cumplida su pretensión. Sería además un remedio que confiere un derecho potestativo, ya que como hemos dicho faculta al acreedor para modificar por medio de su voluntad una situación jurídica. Así, el acreedor modifica la situación de incumplimiento, porque voluntariamente retiene un bien del deudor hasta que este cumpla con el crédito.

Creemos que el derecho de retención es un remedio contractual, que puede incluirse en la serie de remedios que tiene el acreedor para conservar el contrato, asegurar el cumplimiento de las obligaciones y aminorar los daños que el incumplimiento acarree. Para ejercer este remedio hace falta que se cumplan los requisitos de incumplimiento de la obligación, así como los requisitos propios del derecho de retención. Para verificarlo veremos si se encuentra inmerso en el paradigma del nuevo Derecho de contratos: la Convención de Viena sobre compraventa internacional de mercaderías.

\section{Supuestos de retención en la Convención de Viena}

La aplicación de la Convención de Viena se acota a un solo contrato: el de compraventa internacional de mercancías. Por tanto, los supuestos de derecho de retención, de existir en la Convención, se aplicarán solo en este ámbito. Al examinar la Convención se revelan a primera vista tres artículos (7 I.2, 85 y 86) que se aproximan al remedio del derecho de retención. En los puntos que siguen los analizaremos para determinar si se trata realmente de supuestos de derecho de retención dentro de la Convención de Viena, tal y como lo hemos configurado en las páginas anteriores.

\section{A. Detención de las mercancías por incumplimiento previsible del comprador (artículo 71.2)}

El artículo 7 I de la Convención de Viena ${ }^{38}$ trata sobre el incumplimiento previsible. En este caso nos interesa analizar el numeral 2 que establece el derecho

38 Convención de Viena. Art. 7 I: “I) Cualquiera de las partes podrá diferir el cumplimiento de sus obligaciones si, después de la celebración del contrato, resulta manifiesto que la otra parte no cumplirá una parte sustancial de sus obligaciones a causa de: a) un grave menoscabo de su capacidad para cumplirlas o de su solvencia, o b) su comportamiento al disponerse a cumplir o al cumplir el contrato. 2) El vendedor, si ya hubiere expedido las mercaderías antes de que resulten evidentes los motivos a que se refiere el párrafo precedente, podrá oponerse a que las mercaderías se pongan en poder del comprador, aun cuando éste sea tenedor de un documento que le 
del vendedor a impedir la entrega de las mercancías al comprador, aunque estas se encuentren en tránsito.

Se trata de un derecho que puede ejercer solamente el vendedor, aplicable cuando las obligaciones son recíprocas. En otras palabras, el requisito del sinalagma debe cumplirse. No es lícito que el vendedor quiera suspender sus obligaciones para instar al comprador a cumplir con una obligación menor ${ }^{39}$. Además, este supuesto es aplicable cuando las condiciones estén dadas para pensar que habrá un incumplimiento previsible del contrato. La idea general de este "derecho a diferir" es evitar que el vendedor cumpla su obligación con el riesgo serio de no recibir la prestación convenida ${ }^{4}$.

\section{Requisitos}

Para que haya lugar a la aplicación de este artículo es necesario que la obligación del comprador aún no sea exigible, que el vendedor haya enviado las mercancías y que los motivos de que habrá un incumplimiento previsible se hayan evidenciado luego del contrato. Analicemos cada uno de estos requisitos.

En primer lugar, la obligación aún no debe ser exigible, de modo que este artículo puede aplicarse solamente antes de que se cumpla el plazo. En consecuencia, no da derecho a suspender las obligaciones cuando la obligación ya es exigible. Para estos casos la Convención prevé otros remedios ${ }^{4}$. Al no ser exigible la obligación, el comprador no está obligado a cumplir, sino a dar una garantía de futuro cumplimiento. Es un self help remedy del que puede hacer uso el vendedor cuando exista un riesgo de cumplir con su obligación y no recibir nada a cambio ${ }^{42}$.

El segundo requisito es que el vendedor ya haya enviado las mercaderías, es decir, que estas hayan salido de sus bodegas hacia las manos del comprador y se encuentren en tránsito o en camino de ser entregadas ${ }^{43}$. Por eso se ha dicho que

permita obtenerlas. Este párrafo concierne sólo a los derechos respectivos del comprador y del vendedor sobre las mercaderías. 3) La parte que difiera el cumplimiento de lo que le incumbe, antes o después de la expedición de las mercaderías, deberá comunicarlo inmediatamente a la otra parte y deberá proceder al cumplimiento si esa otra parte da seguridades de que cumplirá sus obligaciones".

39 Gilbey, Stub M., The Convention on International sales of goods: Anticipatory repudiation provitions and developing countries. 38 International and Comparative Law Quaterly, Issue 3, I989, 494.

40 Fountoulakis, Christiana, "Section I. Anticipatory breach and instalment contracts". En INgeborg Schwenzer (edit.), Schlechtriem \& Schwenzer. Commentary on the UN Convention on the International Sale of Goods (CISG), $3 .{ }^{\text {rd }}$ ed., Oxford, Oxford University Press, $2010,95^{\circ}$.

4I Los remedios cuando se ha cumplido el plazo y existe incumplimiento van del artículo 6 I al 65 de la Convención. Fountoulakis, Christiana, "Section i...", cit., i6o9.

42 Fountoulakis, Christiana, "Section i...", cit., 950.

43 Antes de que la mercancía se haya enviado es aplicable el supuesto del artículo 7I.I. 
es un "derecho a detener in transitu" 44 . El cual pudiera ser entendido de manera muy amplia, puesto que abarca todo el tiempo desde que las mercancías fueron enviadas por el vendedor, cuando ya ha perdido la posesión material de ellas, hasta incluso cuando estas lleguen a puerto y se encuentren en los trámites aduaneros en el lugar donde el comprador tiene sus establecimientos comerciales. Pero el comprador no puede haber tomado posesión de ellas; si no, no es posible la aplicación del supuesto 45 .

Este derecho es igualmente aplicable cuando el vendedor ha acordado enviar las mercancías directamente a los clientes del comprador. Incluso si el comprador tuviera un documento que le permita hacerse con las mercaderías, es posible la aplicación de este supuesto ${ }^{46}$.

El tercer y último requisito es que los motivos del incumplimiento previsible sean evidentes luego de la contratación y el envío. En otras palabras, debe existir una amenaza objetiva, por ejemplo: la existencia de procedimiento de cesación de pagos o quiebra contra el comprador ${ }^{47}$. El vendedor, basándose en el principio de la razonabilidad, debe determinar que el comprador no estará en capacidad de cumplir con el contrato y por lo tanto suspende sus obligaciones para evitar la pérdida de las mercaderías y el precio ${ }^{4}$.

\section{Relatividad del derecho}

La última frase del artículo 71.2 establece: "Este párrafo concierne sólo a los derechos respectivos del comprador y del vendedor sobre las mercaderías" 49. En otras palabras, los efectos de este supuesto se producen solo entre el vendedor y el comprador, no afectando la relación entre el comprador y sus clientes, terceros de buena fe que han comprado las mercancías o a los cuales se les ha cedido la carta de porte de ellas ${ }^{5}$. Por tanto, esta frase viene a reafirmar lo establecido en el artículo $4 \mathrm{~b}$ de la Convención, donde se señala que "los efectos que el contrato pueda producir sobre la propiedad de las mercancías vendidas" escapa del ámbito de aplicación de la Convención.

Fountoulakis, Christiana, "Section i...", cit., 960.

En ese caso serán aplicables otros artículos de la Convención como del 6r al 64 y del 74 al 77.

Fountoulakis, Christiana, "Section i...", cit., 960-96r .

Fountoulakis, Christiana, "Section i...", cit., 995-996.

Fountoulakis, C. "Section I...", cit., 962-963. Sobre el principio de la razonabilidad, véase Oviedo Albán, J. "Los principios generales...", cit., io 2.

La Secretaría propuso agregar la siguiente frase: "Este párrafo concierne sólo a los derechos respectivos del comprador y del vendedor sobre las mercaderías y no afecta a las obligaciones de los transportistas y otras personas"; la última parte fue borrada. Bennett, Trevor. "Article 7 I". En C. M. Bianca y J. M. Bonell, Commentary on the International Sales Law. The ig8o Vienna Sales Convention, Milán, Giuffrè, I987, 5 I 7 .

Honnold, J. O. Uniform Law..., cit., 557. 
Tampoco afecta las relaciones entre el transportista y el comprador. De hecho, la Convención no obliga al transportista a acatar la orden del vendedor de detener las mercaderías. Si el transportista detiene las mercaderías voluntariamente, se expone a una demanda por daños interpuesta por el comprador. Por otro lado, el vendedor, en virtud de su derecho a detener las mercaderías en tránsito, puede solicitarle al comprador que no tome ninguna medida en contra del transportista. El vendedor podría dar la orden de detención directamente al transportista, o bien solicitar la detención por vía judicial, en virtud del contrato entre el vendedor y el transportista. Fountoulakis indica que este derecho puede ejercerse solicitando una medida cautelar al tribunal competente. La forma, es decir, los requisitos procesales de la medida cautelar, se llevará a cabo tomando en cuenta la lex fori. En cuanto al fondo, deberán reunirse los requisitos establecidos en la Convención de Viena ${ }^{5}$. Opinamos que debido al dinamismo del comercio internacional esta solicitud es poco práctica por las usuales dilaciones de los tribunales. Será la ley aplicable al contrato la que determinará si el transportista deberá cumplir la orden de detención $5^{2}$.

Concordamos con la doctrina en que debido a esta frase este derecho del vendedor es limitado y de relativa eficacia ${ }^{53}$.

\section{Efectos de la detención}

Los efectos de la aplicación de este supuesto se concatenan. En primer lugar, el vendedor debe informar inmediatamente al comprador sobre la detención del envío de las mercaderías, luego de esto el comprador puede dar caución que garantice el futuro cumplimiento y como consecuencia habrá una extensión del tiempo o reajustes de los plazos de cumplimiento. Pasemos a analizar estos efectos.

El primer efecto se encuentra en el numeral tercero del artículo 7 I cuando la Convención insta al vendedor a informar "inmediatamente" al comprador antes o después de la detención de las mercaderías. A pesar de lo enfática que es la Convención en este punto, parte de la doctrina establece que la falta de comunicación no impide que el vendedor ordene la detención de las mercancías en tránsito y con esto se arriesga solamente a una posible demanda de indemniza-

5 I Enderlein, F. y Dietrich M., International Sales Law, Oceania Publications, I992, 288; FounTOULAKIs, C., "Section I...", cit., 963 .

52 Fountoulakis, C., "Section I...", cit., 962. La aplicación de esta norma acarrea otro problema: la detención de las mercaderías en tránsito puede entrar en conflicto con leyes internas o internacionales. Bennett, T., "Article 7I", cit., 5 I 7 .

53 Bennett, T., "Article 7I", cit., 520-52 I; Honnold, J. O., Uniform Law for International Sales under the 1980 United Nations Convention, The Netherlands, Kluwer Law International, 2009, 556; Calvo Caravaca, A., "Disposiciones...", cit., 567; Fountoulakis, C., "Section i...", cit., 962 . 
ción ${ }^{54}$. Opinamos que la Convención en este punto es clara, otorgando una carga de comunicación al vendedor para el ejercicio de este derecho -práctica usual dentro de la tradición de Viena-, por lo que no es posible obviarlo55. La falta de este requisito expresamente establecido por la Convención dará lugar al pago de daños y perjuicios. Ahora bien, estará en manos del juez del caso evaluar si este artículo fue ejercido debidamente ${ }^{5}$.

El segundo efecto es una suerte de paliativo para el comprador, dado que, una vez informado de la suspensión del vendedor, puede otorgar "seguridades suficientes" que garanticen su futuro cumplimiento. Pero esta garantía debe ser efectivamente otorgada, no basta el simple anuncio o la promesa de darla57. Así mismo, el otorgamiento de seguridades suficientes trae en consecuencia otro efecto: la suspensión del derecho del vendedor a detener las mercaderías ${ }^{5}$, es decir, la suspensión cesa y el vendedor deberá poner las mercancías nuevamente en camino para ser entregadas al comprador.

En el caso de que el comprador otorgue caución, se cumple otro efecto: el de la extensión del tiempo o reajuste de los plazos para el cumplimiento del contrato. Como hemos dicho, cuando el comprador otorga las "seguridades suficientes" de las que habla el artículo, cesa la suspensión, pero mientras permaneció la suspensión puede que los plazos originales de cumplimiento hayan caducado, por lo que será necesario que las partes acuerden nuevos plazos de cumplimiento de las obligaciones ${ }^{59}$.

\section{4. ¿Es el derecho del vendedor a detener la mercancía un derecho de retención?}

En el segundo numeral del artículo 7 I de la Convención se lee que el vendedor que ya hubiere enviado las mercaderías, antes de que resulten evidentes los

54 Fountoulakis, C., "Section i...", cit., 959.

55 La jurisprudencia ha determinado inapropiada la aplicación del supuesto cuando no están dados los requisitos para ejercer el derecho a detener en tránsito, caso n. ${ }^{\circ} \mathrm{CISG} / 2005 / 08$ de 2005 China vs. Rusia, http://cisgw3.law.pace.edu/cases/0502 24c2.html; caso n. ${ }^{\circ} 45^{/ 2003}$ de 2004, España, http://cisgw3.law.pace.edu/cases/040205s4.html

${ }_{5} 6$ El ejercicio ilícito del supuesto puede traer como consecuencia el pago de daños y perjuicios tanto para el vendedor como para el comprador en virtud de los artículos 45 y 6I de la Convención de Viena. Caso n. ${ }^{\circ}{ }_{32} \mathrm{CrO}_{14} / 90-4 \mathrm{I}$, Italia vs. Alemania, http://cisgw3.law.pace.edu/ cases/9гог 3 I gi.html

57 Honnold, J. O., Uniform Law for International..., cit., 39i ; Fountoulakis, C., "Section i...", cit., 965 .

$5^{8}$ Honnold, J. O., Uniform Law for International..., cit., 39i ; Fountoulakis, C., "Section i...", cit., 963 .

59 Honnold, J. O., Uniform Law for International..., cit., 393; Fountoulakis, C., "Sección i...", cit., 967 . 
motivos de un incumplimiento previsible, "podrá oponerse"60 a que estas sean entregadas al comprador. Calvo Caravaca sostiene que este numeral contempla un derecho de retención stricto sensu ${ }^{6}{ }^{I}$, mientras que otra parte de la doctrina afirma que se trata de un derecho a suspender las obligaciones en la modalidad de detener in transitu (right of stoppage) ${ }^{62}$. En las siguientes líneas trataremos de dilucidar esto.

En primer lugar, en el derecho de retención se detenta una cosa del deudor. En el supuesto del artículo 7 I las mercaderías pueden no ser aún del deudor. Recordemos que la deuda no es exigible y el deudor no ha pagado las mercaderías. Este artículo no se refiere a retener una cosa del comprador, sino a detener las mercancías mientras se encuentren en camino de ser entregadas. Es un derecho de suspensión en una faceta más acotada, la de detener el envío de la cosa mientras se encuentre en camino al destino.

En segundo lugar, en el derecho de retención no se le exige al deudor que dé "seguridades suficientes" para garantizar el cumplimiento como lo hace el numeral 2 del artículo 7r. La cosa retenida es en sí la garantía, la seguridad del cumplimiento de la otra parte. En el derecho de retención, solamente el pago de la obligación produce la extinción del derecho y el deber de restitución de la cosa.

Por lo tanto, el artículo 7 I de la Convención de Viena, si bien es un remedio en caso de posible incumplimiento del contrato, no establece un derecho de retención, sino un derecho a suspender el cumplimiento ${ }^{63}$. Se trata de un caso de excepción de incumplimiento previsible, que opera como una medida de defensa del acreedor cuando existe un riesgo evidente de que la otra parte no podrá cumplir con su prestación, suspendiendo el acreedor el cumplimiento de la propia obligación hasta que el deudor cumpla o dé garantías de futuro cumplimiento ${ }^{64}$.

60 En su versión en inglés, la Convención hace lo propio: Article 7r: "2) If the seller has already dispatched the goods before the grounds described in the preceding paragraph become evident, be may prevent the handing over the goods to the buyer even though the buyer holds a document which entitles him to obtain them...". United Nations Convention of Contracts for International Sales of Goods, New York, 20Io; disponible en http://www.uncitral.org/pdf/english/ texts/sales/cisg/Vio56997-CISG-e-book.pdf; consultado el 25 de abril de 2016 (resaltado por la autora).

6i Calvo Caravaca, A. "Disposiciones comunes a las obligaciones...", cit., 567 y ss.

62 Fountoulakis, C. "Section I...”, cit., 960 y ss.

63 Honnold, J. O. Uniform Law for International..., cit., 548.

64 La excepción de incumplimiento previsible se encuentra en diferentes ordenamientos jurídicos, como en el derecho alemán en el artículo 32 I del вGв aplicado como norma general para todo tipo de obligaciones, en el Codice italiano en el artículo I46 I donde también es de carácter general, en el Code francés está en el artículo I6 13, pero solamente referente a la compraventa, equivalente al artículo i 882 del Código Civil colombiano y al i 826 del Código Civil Chileno aunque Claro Solar, L., Explicaciones..., cit., 496, es el único autor que sostiene que este artículo se trata de un supuesto de derecho de retención-. También se dice que es una institución que se originó en el Common Law inglés a partir del caso Hochster vs. De La Tour (i853) i i 8 Eng. Rep. 922 y se le denomina anticipatory non-performance o anticipatory breach of contract; GILBEY, Stub M., "The Convention on International sales of goods: Anticipatory repudiation provi- 
Vendría a ser una modalidad de la excepción de contrato no cumplido ${ }^{65}$. Se diferencia de la exceptio non adimpleti contractus en que las prestaciones aún no son exigibles, pero existe un riesgo de un futuro incumplimiento que permite la excepción de suspender hasta que el deudor cumpla u otorgue garantías.

En la excepción por incumplimiento previsible el riesgo debe hacerse manifiesto luego de la celebración del contrato ${ }^{66}$, concordando con lo establecido en el artículo 7 I de la CIsG in comento. El bien protegido es la confianza o la pérdida de ella en que el negocio se realice y en consecuencia se pierda el precio o las mercancías ${ }^{67}$.

\section{B. Conservación de las mercaderías (artículos 85 y 86)}

La conservación de las mercaderías es una carga material que impone la Convención de Viena, en ciertas circunstancias, a la parte que se encuentra en mejor posición para guardar de ellas. Los artículos 85 y 86 de la cisG establecen que en ciertas circunstancias tanto comprador como vendedor deben conservar las mercaderías a nombre y cargo de la contraparte. Evaluemos este supuesto para determinar si se trata de un derecho de retención.

\section{Circunstancias bajo las cuales se conservan las mercaderías}

El artículo 85 de la Convención establece que ante el incumplimiento del comprador el vendedor debe tomar todas las medidas necesarias para la conservación de las mercaderías ${ }^{68}$. De igual manera, el artículo 86 señala que, cuando el

tions and developing countries", International and Comparative Law Quaterly, vol. 38, I989, 477; también se encuentra en el Uniform Comercial Code de los Estados Unidos (Section 2-6o9); Enneccerus, L., Tratado de Derecho Civil, t. II, Blas Pérez González y José Alguer (trads.), Barcelona, Bosch, I954, I69; Larenz, K., Derecho de Obligaciones, t. I, Jaime Santos Briz (trad.), Madrid, Editorial Revista de Derecho Privado, i958, 27 I; Hedemann, J. W., Tratado de derecho civil, vol. III: Derecho de obligaciones, Jaime Santos Briz (trad.), Madrid, Editorial Revista de derecho Privado, I958, I04.

65 Enneccerus, L., Tratado de Derecho Civil..., cit., i69; Abeliuk Manasevich, R., Las Obligaciones..., cit., i i i 8; Mejías Alonzo, Claudia, "La excepción de contrato no cumplido, un análisis de su aplicación en la jurisprudencia nacional reciente y en la doctrina", Revista de Derecho Universidad Católica del Norte, vol. 2 I, n. ${ }^{\circ}$ I, 2014, I 23.

66 Enneccerus, L., Tratado de Derecho Civil..., cit., I69; Larenz, K., Derecho de Obligaciones..., cit., 27 i; Hedemann, J. W., Tratado de derecho Civil..., cit., I05.

67 Larenz, K., Derecho de Obligaciones..., cit., 27 I; MejÍas Alonzo, Claudia, La excepción de contrato..., cit., I 23 .

68 Convención de Viena: Art. 85: "Si el comprador se demora en la recepción de las mercaderías o, cuando el pago del precio y la entrega de las mercaderías deban hacerse simultáneamente, no paga el precio, el vendedor, si está en posesión de las mercaderías o tiene de otro modo poder de disposición sobre ellas, deberá adoptar las medidas que sean razonables, atendidas las circunstancias, para su conservación. El vendedor tendrá derecho a retener las mercaderías hasta que haya obtenido del comprador el reembolso de los gastos razonables que haya realizado". 
comprador tenga la intención de rechazar las mercaderías -por incumplimiento del vendedor- y se encuentra en posesión de ellas, deberá tomar las medidas razonables para su conservación ${ }^{69}$.

Entonces, las circunstancias bajo las cuales se deben conservar las mercaderías son tres: el incumplimiento de la contraparte, la suspensión de las obligaciones del acreedor y la tenencia material de las mercaderías.

En el caso del artículo 85, el incumplimiento del comprador puede evidenciarse de dos maneras: I) demora en la recepción de las mercancías o 2) impago del precio cuando la entrega del bien y el pago deban hacerse simultáneamente. La primera causal entraña varias situaciones. Barrera Graf considera demora no solo la no recepción de las mercaderías, sino también el incumplimiento de las obligaciones correlativas de lugar, modo, tiempo e incluso entrega de documentos tal y como fueron convenidos en el contrato ${ }^{70}$. La segunda causal se refiere al incumplimiento del pago, que a la letra de la Convención debe ser de cumplimiento simultáneo, aunque autores como sostienen que se pueden incluir los casos de cumplimiento diferido del pago $^{71}$. Idea que vemos posible tomando en cuenta la primera causal de incumplimiento y en concordancia con los artículos $5^{8}$ y 59 de la Convención aplicables en los casos de cumplimiento diferido o cuando no se ha establecido claramente en el contrato la fecha del pago del comprador. Por lo que puede decirse que el artículo 85 es aplicable tanto cuando las partes han establecido una fecha de pago como cuando no lo han hecho.

En el artículo 86 el comprador tiene la intención de rechazar las mercaderías dado el incumplimiento del vendedor que puede producirse por el retraso en el envío de las mercancías, que las haya enviado incompletas o que haya enviado mercancías no conformes con el contrato ${ }^{72}$. El comprador puede ejercer su dere-

69 Convención de Viena: Art. 86: “I) El comprador, si ha recibido las mercaderías y tiene la intención de ejercer cualquier derecho a rechazarlas que le corresponda conforme al contrato o a la presente Convención, deberá adoptar las medidas que sean razonables, atendidas las circunstancias, para su conservación. El comprador tendrá derecho a retener las mercaderías hasta que haya obtenido del vendedor el reembolso de los gastos razonables que haya realizado. 2) Si las mercaderías expedidas al comprador han sido puestas a disposición de éste en el lugar de destino y el comprador ejerce el derecho a rechazarlas, deberá tomar posesión de ellas por cuenta del vendedor, siempre que ello pueda hacerse sin pago del precio y sin inconvenientes ni gastos excesivos. Esta disposición no se aplicará cuando el vendedor o una persona facultada para hacerse cargo de las mercaderías por cuenta de aquél esté presente en el lugar de destino. Si el comprador toma posesión de las mercaderías conforme a este párrafo, sus derechos y obligaciones se regirán por el párrafo precedente".

Barrera Graf, J., Commentary of the International Sales Law..., cit., 282.

Barrera Graf, J., Commentary of the International Sales Law..., cit., 283.

72 En el caso n. 867 de 2008, Eslovenia vs. Italia, http://cisgw3.law.pace.edu/cases/o8 I 2 I riz. html, el comprador rechaza las mercancías por inconformidad, debiendo pagar el vendedor los gastos de la conservación de las mercaderías rechazadas. Sobre falta de conformidad en las mercancías, consultar: Oviedo Albán, Jorge, "La protección del comprador por falta de conformidad material en la compraventa internacional de mercaderías", Revista de Derecho Privado, n. ${ }^{\circ}$ 26, 2014 4, 2 I9-2 53; Vidal Olivares, Álvaro, "Efectos particulares de la falta de conformidad 
cho a rechazar las mercaderías luego de un tiempo razonable en el cual evidencie la no conformidad de la mercadería recibida ${ }^{73}$.

Habida cuenta del incumplimiento de la contraparte, requisito de aplicación de los artículos 85 y 86, se genera la segunda circunstancia bajo la cual se produce la conservación de las mercaderías; esta es la suspensión de las obligaciones del acreedor. En el artículo 85 se produce solamente en la segunda causal de incumplimiento del comprador, esta es cuando el comprador no ha pagado el precio. Es el derecho del vendedor a suspender su obligación de entregar las mercaderías, por lo tanto es una excepción de contrato no cumplido ${ }^{74}$, debido a que la falta del comprador permite al vendedor no cumplir su propia prestación sin caer este en incumplimiento. En consecuencia, es la falta de reciprocidad en el cumplimiento de la prestación del comprador lo que produce la excepción a favor del vendedor.

Esta circunstancia se da solamente en el segundo caso de incumplimiento del comprador, porque en el primero -el retraso en la recepción de las mercaderías- el vendedor ya ejecutó su prestación, puso a disposición del comprador las mercancías, seguramente porque las obligaciones eran de cumplimiento diferido, o incluso el comprador pudo haber pagado el precio incumpliendo solamente en el momento de la recepción. En cualquier caso, el vendedor ya ha cumplido con su obligación y no cabe tal suspensión de su parte. Es por ello que la excepción se da solo en el segundo caso de incumplimiento, cuando el comprador no ha pagado el precio.

En el caso del artículo 86, como ya hemos dicho, estamos ante un incumplimiento por parte del vendedor, lo que justifica el rechazo de las mercaderías por parte del comprador. Este derecho a rechazar no es más que un derecho de suspensión, ya que el comprador, ante el incumplimiento del vendedor, suspende su obligación de recibir las mercaderías ${ }^{75}$. Nuevamente estamos frente a una excepción de contrato no cumplido, porque el incumplimiento del vendedor permite al comprador suspender su obligación de recibir las mercancías.

Esto nos lleva a la tercera circunstancia: la tenencia material de las mercaderías. En el artículo 85 el vendedor debe mantenerse en posesión de las mercaderías. La posesión implica la tenencia física o el poder de disposición; esto requiere que las mercancías se encuentren en manos de un agente o empleado

de las mercaderías en la compraventa internacional", Revista de Derecho de la Pontificia Universidad Católica de Valparaíso, n. ${ }^{\circ}$ 26, 2005, 559-593.

73 Barrera Graf, Jorge, Commentary of the International Sales Law ..., cit., 286; Montes, Vicente, "Conservación de las mercaderías"..., cit., 689.

74 Guarda relación con el artículo 58 de la Convención de Viena.

75 La recepción de las mercaderías es una obligación del comprador establecida en el artículo 60 de la Convención. 
del vendedor ${ }^{7}$. En el artículo 86 ocurre otro tanto: las mercancías tienen que haber sido recibidas o haber sido enviadas al comprador, es decir que estén a disposición del comprador con las debidas estipulaciones que se han acordado en el contrato. En ambos artículos la Convención insta al acreedor a tomar posesión de las mercaderías a nombre y cargo de la contraparte, debiendo tomar todas las medidas que sean necesarias y razonables para su conservación 77 . En concreto, las medidas que se deberán tomar solo se sabrán en cada caso en particular ${ }^{78}$, las cuales siempre deberán basarse en el principio de la razonabilidad79.

\section{2. ¿Es el deber de conservación de las mercaderías un derecho de retención?}

La conservación de las mercaderías a la que está obligado el vendedor o el comprador, según el caso, es un deber que asigna la Convención. Es una carga material que se le impone a la parte que está en mejor posición de conservar las mercaderías, ya sea porque se encuentra en posesión de ellas o porque no existe en el lugar algún representante, agente o dependiente de la contraparte que se haga cargo de ellas. Con lo cual deberá tomar posesión a nombre y a cuenta del deudor.

En realidad, la obligación de conservar las mercaderías es ajena al contrato de compraventa suscrito entre comprador y vendedor, resultando un efecto legal del incumplimiento ${ }^{80}$. En otras palabras, la Convención le impone la carga de conservar las mercaderías al que está en mejor posición de guardar de ellas, ya que ambas partes están obligadas -en virtud del artículo 77 de la Convención- a ejercitar cualquier acto que aminore las pérdidas, siendo la conservación de las mercaderías una acción que coadyuva a la reducción de las posibles pérdidas que pudieran producirse.

Por lo tanto, con la conservación de las mercaderías la Convención no otorga ningún derecho en sí mismo. Por el contrario, es un deber que deben asumir tanto vendedor como comprador para evitar las pérdidas de su contraparte y

76 Barrera Graf, J., Commentary of the International Sales Law..., cit., 283; Bacher, K., "Section vi Preservation of the Goods...", cit., I I 50.

77 Adame Goddard, Jorge, "Las obligaciones del comprador en la compraventa internacional", Revista de Derecho Privado, n. ${ }^{\circ}$ 9, I992, 496; Bacher, KLaus, "Section vi Preservation of the Goods...”, cit., I I 58 .

78 En ocasiones el asegurar las mercaderías puede ser parte de las medidas necesarias para su conservación. Caso n. ${ }^{\circ} 2087$ de 2006, Bélgica vs. Alemania, http://cisgwz.law.pace.edu/ cases/o6o424br.html

79 Bacher, Klaus, "Section vi Preservation of the Goods...", cit., I I 5 I. Sobre el principio de la razonabilidad, consultar: Oviedo Albán, Jorge, "Los principios generales en la Convención de las Naciones Unidas sobre compraventa internacional de mercaderías”, Boletín Mexicano de Derecho Comparado, año 47, n. ${ }^{\circ}$ I4I, 2014, 987-IO2O; y SAidov, DJakhongir, The Law of damages..., cit., I 35 .

8o Barrera Graf, Jorge, Commentary of the International Sales Law..., cit., 284. 
para la asunción de otros derechos. Es más, si no se asume esta obligación el deudor podría demandar en juicio el no ejercicio de esta carga aunado al pago de las pérdidas que haya tenido. Es por esto que afirmamos que la conservación de las mercaderías no constituye un supuesto de derecho de retención dentro de la Convención de Viena, sino que se trata de una carga material que impone la Convención para aminorar las pérdidas que pudieran producirse por el incumplimiento de uno de los actores del contrato.

\section{Retención de las mercancías (artículos 85 y 86)}

La Convención de Viena exige tanto a vendedor (art. 85) como a comprador (art. 86) que conserven las mercaderías a nombre y cargo de su contraparte, lo que genera un crédito por los gastos de conservación, el cual puede dar lugar a la retención de las mercaderías hasta que se haya obtenido el reembolso de los gastos. Examinaremos si este supuesto se trata realmente de un caso de derecho de retención, tal y como lo hemos configurado en páginas anteriores.

\section{Circunstancias bajo las cuales se retienen las mercancías}

Las circunstancias bajo las cuales se retienen las mercancías son dos incumplimientos: el primero -que podríamos llamar el incumplimiento de la obligación principal- es la falta de pago del comprador (en el caso del artículo 85) o el envío del vendedor de mercancía no conforme que da lugar al rechazo de las mercancías por parte del comprador (en el caso del artículo 86). Frente a este incumplimiento, la Convención insta a la parte que se encuentre en mejor posición a conservar las mercaderías. Como consecuencia de la conservación se generan gastos y la falta de pago de estos gastos de conservación genera a su vez el segundo incumplimiento que da lugar a la retención de las mercaderías hasta el reembolso de dichos gastos.

Antes de seguir con el derecho de retención, detengámonos para hablar de los gastos por la conservación. Estos deben ser significativos y proporcionales con el valor de las mercaderías, es decir, no cualquier gasto genera la retención de las mercaderías. Además, el importe de los gastos dependerá de las medidas que se deben tomar para la conservación de las mercaderías, que, como dijimos, dependerá de cada caso. Los gastos deben ser razonables y deben estar enmarcados dentro del principio de razonabilidad que informa a toda la Convención. Por lo que en caso de disputa será el juez el que determine qué gastos son razonables, atendiendo a las características de las mercancías guardadas ${ }^{8 \mathrm{I}}$.

8I Los gastos deben ser razonables. Corresponderá al acreedor la carga de la prueba, por lo cual deberá probar cualquier gasto que quiera que se le reembolse: Bacher, KLAus, "Section vi Preservation of the Goods...", cit., I I 52. En caso de controversia será el juez el que determine 
Volviendo a la retención de las mercaderías, la Convención establece -tanto en el artículo 85 para el vendedor como en el artículo 86 para el caso del comprador- la facultad de retener las mercaderías hasta el "reembolso de los gastos razonables que haya realizado”. Es una suerte de garantía, que será válida hasta el reembolso de los gastos erogados por la conservación de las mercaderías. Es decir, la retención cesa cuando el comprador ha pagado los gastos de la conservación de las mercaderías ${ }^{82}$. Incluso si el comprador paga el precio de las mercancías, persiste la retención como garantía del pago de los gastos de conservación. En otras palabras, la retención es independiente de la excepción de contrato no cumplido que ejerce el acreedor ante el incumplimiento del deudor ${ }^{8}$. Si bien ambos se aplican por el incumplimiento del comprador, el cese de uno no implica el cese del otro.

Determinadas las circunstancias en las cuales se enmarca la retención de las mercaderías, pasemos a analizar si se trata verdaderamente de un supuesto de derecho de retención tal y como lo hemos establecido en acápites anteriores.

\section{2. ¿Es la retención de las mercaderías un supuesto de derecho de retención?}

Como hemos dicho, el derecho de retención es una medida de autotutela que tiene el acreedor para garantizar un crédito frente al deudor. Se trata de un remedio que puede ejercer potestativamente el acreedor frente al incumplimiento del deudor, para el cual es necesario que se den unos requisitos para su aplicación. Frente a esto, cabe preguntarse si la figura que vislumbramos como retención en la Convención de Viena es en realidad un supuesto de derecho de retención. Examinemos cada uno de estos requisitos que ha aportado la doctrina sobre el derecho de retención a la luz del supuesto de la Convención que estamos estudiando.

El primer requisito es que el derecho de retención es de carácter legal; en otras palabras, lo establece la norma. En este caso podemos decir que este requisito se da claramente, puesto que la Convención establece en sus artículos $85 \mathrm{y}$ 86 la retención de las mercaderías ante la falta de pago de los gastos de conservación de estas.

qué gasto es razonable: caso n. ${ }^{\circ} 2087$ de 2006 , Bélgica vs. Alemania, http://cisgw3.law.pace.edu/ cases/o60424bi.html

82 Perales Viscasillas, María del Pilar, "El contrato de compraventa internacional de mercaderías. (Convención de Viena de I980)", 200I, disponible en http://www.cisg.law.pace.edu/cisg/ biblio/perales r.html; consultado: 28 de junio del 20 I6; así también se ha visto establecido en la jurisprudencia internacional, caso n. ${ }^{\circ} 20$ de I994, Suiza vs. Alemania, http://cisgw3.law.pace. edu/cases/9405 I 7si.html, donde el vendedor tiene el derecho a retener las mercaderías hasta que se le reembolsen los gastos de conservación.

83 Sobre la excepción de contrato no cumplido de la que hablamos en el punto anterior acerca de Conservación de las mercaderías. 
El segundo requisito habla sobre la tenencia lícita de la cosa; es decir, la cosa o para ser más precisos las mercancías en el caso de la Convención de Viena están en manos del acreedor de manera lícita, legítima, libre de vicios, por el deber de conservación que debe ejercer el acreedor. Además, en la Convención se conserva lo ajeno, al igual que ocurre en el derecho de retención. Debido a que las mercancías se conservan a nombre y cargo del deudor (vendedor o comprador). Aunque la propiedad de las mercancías escapa del ámbito de aplicación de la Convención de Viena, en virtud del artículo 4b, podemos afirmar que las mercancías se guardan y retienen como ajenas cuando la Convención establece que la retención perdura hasta que el deudor realiza el reembolso de los gastos de conservación, confirmándose así la ajenidad de la cosa retenida ${ }^{84}$.

El tercer requisito trata sobre el crédito, el cual debe ser cierto, líquido y exigible. En el supuesto de retención de los artículos 85 y 86 de la Convención, el crédito cumple con estas características. Este crédito es cierto porque deviene de los gastos razonables que se hayan realizado para la conservación de las mercaderías. El crédito es líquido dadas sus características que son los gastos de conservación, porque lo que deberá entregar el deudor será una suma de dinero específica. La exigibilidad de la deuda es un aspecto muy importante porque el hecho de que el crédito sea efectivamente exigible da pie a que las mercancías sean retenidas hasta que se reembolse el monto total de los gastos de conservación.

El cuarto y último requisito del derecho de retención es la conexión entre el crédito y la cosa retenida. Sobre este requisito, la doctrina ha dicho que puede ser una conexión directa o indirecta con la cosa retenida. En el supuesto de retención de los artículos 85 y 86 de la Convención, se distingue una conexión directa entre el crédito y la cosa retenida porque el crédito se genera por los gastos de conservación de las mercaderías retenidas, evidenciándose así la estrecha conexión entre el crédito y la cosa retenida.

Dicho lo anterior, podemos afirmar que el supuesto de retención de los artículos 85 y 86 de la Convención de Viena establece verdaderamente un derecho de retención, tomando en cuenta los requisitos que han sido aportados por la doctrina para esta institución. El acreedor -ya sea vendedor o comprador- tiene derecho a retener las mercancías hasta que se le reembolsen los gastos erogados por la conservación de las mismas, y este derecho se extingue únicamente con el pago de los gastos de conservación.

Valga acotar que la aplicación del derecho de retención debe ser justificada y proporcional. Por ejemplo, en el caso del vendedor no puede ejercer el derecho

84 Esta ajenidad se percibe de manera patente en el artículo 86 de la Convención cuando establece: "[e]l comprador [...] deberá tomar posesión de ellas [las mercaderías] por cuenta del vendedor, siempre que ello pueda hacerse sin pago del precio y sin inconvenientes ni gastos excesivos" (cursivas nuestras). 
de retención en aquellos casos en que el comprador ha prestado una garantía que asegure la devolución de los gastos, o en los casos en que el importe de dichos gastos sea pequeño. Por tanto, el acreedor del derecho de retención deberá actuar en atención al principio de razonabilidad y el principio de la buena fe, informador del texto en su conjunto ${ }^{85}$.

\section{Configuración del derecho de retención en la Convención de Viena}

Establecida la existencia del derecho de retención en la Convención de Viena, pasemos a examinar con mayor detención su configuración en este cuerpo normativo.

\section{Características}

El derecho de retención se produce por un incumplimiento que se da fuera del contrato $^{86}$, es decir, porque el acreedor (vendedor o comprador) tiene la carga material de conservar las mercaderías y debido a la falta de pago de los gastos de conservación de estas se le otorga el derecho a retenerlas hasta ver satisfecho su crédito. Por lo tanto, el derecho de retención en la Convención de Viena es de carácter legal y delimitado a los supuestos establecidos, tal y como señala la doctrina clásica sobre el derecho de retención. Así, el derecho de retención en la Convención de Viena se encuentra solamente establecido en los artículos 85 y 86. Entonces, no es un principio de carácter general, que pueda hacerse valer cuando se conjuguen ciertos requisitos como la detentación de un bien y un crédito insoluto, sino que solamente puede ejercerse en los supuestos establecidos por la Convención. Dicho esto, podemos afirmar que el derecho de retención en la Convención se acoge a la postura legalista dentro de la doctrina, la cual reza que ese derecho está supeditado a supuestos específicos establecidos por la norma, en este caso la Convención de Viena sobre compraventa internacional de mercaderías.

Además, el derecho de retención en la Convención concuerda con la postura estricta propiciada por Díez-Picazo, la cual consagra que el supuesto legal del derecho de retención se refiere al crédito por los gastos hechos en o por la cosa retenida, lo cual concuerda con el derecho de retención que figura en la Convención, que establece el derecho por la falta de pago de los gastos de conservación de las mercancías objeto de la retención.

Por otro lado, el derecho de retención en la Convención opera ipso iure, es decir, no hace falta declaración judicial que la confirme. La labor del juez entra en juego cuando existen controversias en cuanto al pago de los gastos de conser-

85 Jordà Capitán, Eva, Retención posesoria y derecho de retención, Madrid, Dykinson, 20I4, I 28.

86 Ibid. 
vación o la consideración de cuáles gastos son o no razonables. Antes de que el juez conozca de la causa, ya el derecho de retención ha sido ejercido.

Por último, el derecho de retención en la Convención de Viena opera sobre los bienes y contratos enmarcados en su ámbito de aplicación, el cual, recordemos, se trata en la compraventa internacional de mercaderías.

\section{Facultades}

Entre las facultades que contempla la Convención para el ejercicio del derecho de retención está la posibilidad de guardar la mercancía en los depósitos de un tercero, siempre y cuando el gasto no sea excesivo, y a expensas del deudor, en virtud de lo estipulado por el artículo 87 de la Convención de Viena ${ }^{87}$.

Así mismo, la Convención faculta en su artículo $88^{[88]}$ al comprador o vendedor que ha conservado y retenido las mercancías a venderlas, en los siguientes casos: I) por demora excesiva en tomar posesión de las mercaderías, 2) demora en aceptar la devolución de las mercaderías, o 3) demora en pagar el precio. La venta también es permitida 4) cuando por la naturaleza de las mercancías están expuestas a deterioro rápido, o 5) cuando su conservación entraña gastos excesivos. En estos casos la Convención permite que el retenedor venda las mercancías y a su vez cobrar del precio de la venta el importe que ha gastado por la conservación de las mismas ${ }^{89}$.

Vale acotar que los gastos por la conservación de las mercancías muchas veces incluyen gastos de gestión $9^{\circ}$ erogados por la comercialización de las merca-

87 Convención de Viena, art. 87: "La parte que esté obligada a adoptar medidas para la conservación de las mercaderías podrá depositarlas en los almacenes de un tercero a expensas de la otra parte, siempre que los gastos resultantes no sean excesivos".

88 Convención de Viena, art. 88: “I) La parte que esté obligada a conservar las mercaderías conforme a los artículos 85 u 86 podrá venderlas por cualquier medio apropiado si la otra parte se ha demorado excesivamente en tomar posesión de ellas, en aceptar su devolución o en pagar el precio o los gastos de su conservación, siempre que comunique con antelación razonable a esa otra parte su intención de vender. 2) Si las mercaderías están expuestas a deterioro rápido, o si su conservación entraña gastos excesivos, la parte que esté obligada a conservarlas conforme a los artículos 85 u 86 deberá adoptar medidas razonables para venderlas. En la medida de lo posible deberá comunicar a la otra parte su intención de vender. 3) La parte que venda las mercaderías tendrá derecho a retener del producto de la venta una suma igual a los gastos razonables de su conservación y venta. Esa parte deberá abonar el saldo a la otra parte".

89 Caso n. $^{\circ} 753$ I de i994, Austria (comprador) vs. China (vendedor), en que el comprador austriaco reclamó el pago de los gastos con motivo de la conservación de las mercaderías y los gastos de gestión para la posterior venta de las mismas, así como los daños y perjuicios, los cuales el tribunal acogió totalmente, menos los gastos de traslado del nuevo comprador. http://cisgw3.law.pace. edu/cases/94753 rir.html; caso n. ${ }^{\circ} 304$ de I994, Italia (comprador) vs. EeuU (vendedor), en el que el comprador reclama los daños y perjuicios en los que incluye los gastos por la conservación de las mercaderías atinentes del artículo 86 de la cv. http://cisgw3.law.pace.edu/cases/9409o9u r.html

90 Caso n. ${ }^{\circ} 753$ I de i 994, Austria (comprador) vs. China (vendedor), en que el comprador austriaco reclamó el pago de los gastos con motivo de la conservación de las mercaderías y los gastos de gestión para la posterior venta de las mismas, así como los daños y perjuicios, los cuales el 
derías, e incluso la indemnización de perjuicios por los daños que dicha demora pudo acarrear para el afectado ${ }^{9 \mathrm{I}}$.

La venta de las mercaderías, además de ser una facultad, es un efecto del derecho de retención establecido en los artículos 85 y 86 de la Convención, donde se le otorga al acreedor retenedor la facultad o la obligación ${ }^{92}$ de vender las mercancías, lo que se ha denominado en el primer caso (88. I) venta de autoayuda ${ }^{93}$ y en el segundo caso (88.2) venta de emergencia ${ }^{94}$, y con lo resultante de estas ventas el acreedor puede cobrar lo que ha gastado por la conservación de aquellas. Hablamos pues de una compensación95 que brinda la Convención al acreedor que ha cumplido con todas sus obligaciones.

\section{Extinción}

Dentro de la Convención, el derecho de retención se extingue cuando el deudor (comprador o vendedor, según sea el caso) ha pagado los gastos de la conservación de las mercaderías ${ }^{6}{ }^{6}$ Por tanto, no basta el pago del precio de las mercancías. El derecho de retención persiste como garantía del pago de los gastos de conservación.

Otro modo de extinción del derecho de retención dentro de la Convención es el del artículo 88, en el cual el retenedor podrá vender las mercaderías cuando estas sean de carácter perecible y de costoso mantenimiento o cuando ha transcurrido mucho tiempo sin que el deudor pague los gastos de conservación, permitiendo el cobro de los gastos en que incurrió con el resultado de la venta.

\section{El derecho de retención como remedio dentro de la Convención de Viena}

Hemos planteado en puntos anteriores que el derecho de retención es un remedio y como tal contiene el requisito común a todos los remedios: el incumpli-

tribunal acogió totalmente, menos los gastos de traslado del nuevo comprador. http://cisgw3. law.pace.edu/cases/94753 гі ir.html

9I Caso n. 304 de I994, Italia (comprador) vs. EeuU (vendedor), en que el comprador italiano reclama los daños y perjuicios en los que incluye los gastos por la conservación de las mercaderías atinentes del artículo 86 de la cv. http://cisgw3.law.pace.edu/cases/9409o9ur.html

92 Privilegio y deber, respectivamente, según Honnold, John O., Uniform Law for International..., cit., 689 .

93 Bacher, Klaus, "Section vi Preservation of the Goods...”, cit., I930.

94 Bacher, Klaus, "Section vi Preservation of the Goods...", cit., I 933.

95 Montes, Vicente, “Conservación de las mercaderías...”, cit., 696.

96 Perales Viscasillas, María del Pilar, "El contrato de compraventa internacional de mercaderías. (Convención de Viena de I980)", 200 I; disponible en http://www.cisg.law.pace.edu/cisg/ biblio/peralesı.html; consultado: 28 de junio de 20I6; así también se ha establecido en la jurisprudencia internacional: caso n. ${ }^{\circ} 200$ de I994, Suiza vs. Alemania, http://cisgw3.law.pace.edu/ cases/9405 I 7si.html, en el cual el vendedor tiene el derecho a retener las mercaderías hasta que se le reembolsen los gastos de conservación. 
miento; y requisitos distintivos: la tenencia lícita de un bien y la conexión entre el crédito y la cosa retenida.

En los supuestos que hemos determinado como derecho de retención -estos son los artículos 85 y 86- el requisito del incumplimiento está presente. En el primer caso, el incumplimiento lo produce el comprador y se evidencia por la falta de pago oportuno o la demora en el recibimiento de las mercancías. En el segundo caso, el incumplimiento es del vendedor y se traduce en la demora en el envío de las mercaderías, el envío incompleto o envío de mercancías no conforme a lo establecido en el contrato, lo que produce el rechazo de las mercaderías por parte del comprador.

Los requisitos propios del derecho de retención que lo distinguen de los demás remedios son: la tenencia lícita de la cosa y la conexión entre el crédito y la cosa. La tenencia lícita de la cosa en manos del acreedor se produce cuando la Convención insta al acreedor -comprador o vendedor- a conservar las mercaderías a nombre del deudor. Por ende, la tenencia es lícita; de hecho, corresponde a la carga de conservar las mercaderías que establece la Convención. En consecuencia, se genera un crédito a favor del retenedor por los gastos de conservación de las mercaderías, verificándose la conexión entre la cosa y el crédito.

Así mismo, el derecho de retención, al igual que los demás remedios, se ejerce ante el incumplimiento del deudor; en otras palabras, se activa por la falta de pago de los gastos de conservación, pudiendo el acreedor ejercer el remedio de manera potestativa. El derecho de retención a su vez cumple con la función de todo remedio, que es la de evitar o aminorar las pérdidas que el incumplimiento del deudor pudiera ocasionar no solo para el acreedor, sino para el mismo deudor, ya que, recordemos, ambas partes están obligadas a evitarse pérdidas en virtud del artículo 77 de la Convención de Viena.

Es por esto que podemos afirmar que el derecho de retención es uno de los remedios que establece la Convención de Viena con los que cuenta el acreedor para paliar los efectos del incumplimiento, aminorar las pérdidas, mantener la vigencia del contrato y asegurar el pago del crédito, que en este caso se trata de los gastos realizados por la conservación de las mercaderías.

\section{Conclusiones}

Luego de analizar todos los supuestos de la Convención de Viena que de una u otra forma tenían relación con el derecho de retención, presentamos nuestras conclusiones.

El derecho de retención es la facultad que tiene el acreedor de detentar un bien del deudor para garantizar el cumplimiento de las obligaciones contraídas. Se trata, por lo tanto, de un derecho accesorio y excepcional, de modo que es necesaria la existencia de un incumplimiento para su ejercicio. Por ser una medida de defensa del acreedor frente al incumplimiento, sostenemos que se trata de un 
remedio del que puede hacer uso voluntariamente el acreedor, siempre que se evidencien los requisitos de aplicación.

En el examen realizado a ciertos artículos de la Convención pudimos constatar que en el supuesto del artículo 7 I.2, pese a que a primera vista se lo pudiera confundir con un supuesto de derecho de retención, realmente se trata de un caso de excepción de contrato no cumplido en su modalidad de excepción de incumplimiento previsible, dado que la obligación aún no es exigible, pero existe un riesgo objetivo de futuro incumplimiento que permite al vendedor la excepción de suspender sus obligaciones hasta que el comprador rinda caución en un tiempo razonable.

En cambio, el derecho de retención se encuentra establecido en la Convención de Viena en los artículos 85 y 86, cuando luego de imponer la carga de conservación de las mercaderías otorga el derecho a retenerlas hasta que el deudor pague los gastos por su conservación. En consecuencia, se trata de un derecho legal porque se encuentra delimitado en la Convención a determinados supuestos, concordando con la postura legalista imperante sobre el derecho de retención. Además, se ajusta a la postura estricta de la doctrina, la cual delimita el supuesto legal del derecho de retención a los gastos producidos en la cosa o por la cosa retenida.

Así mismo, el incumplimiento que genera el derecho de retención en la Convención se configura fuera del contrato suscrito entre las partes, dado que el deber de conservación de las mercaderías que impone la Convención y que trae como consecuencia el derecho de retención son obligaciones no establecidas en el contrato. Entre las facultades que otorga la Convención para ejercer el derecho de retención está la posibilidad de conservar las mercancías en depósitos de un tercero (art. 87) y el vender las mercaderías retenidas compensando con lo ganado en esta venta los gastos de conservación (art. 88). El derecho de retención dentro de la Convención se extingue cuando se han pagado los gastos de conservación de las mercaderías, sin perjuicio de haber cumplido con la obligación principal.

Concluimos diciendo que el derecho de retención en la Convención de Viena forma parte del conjunto de remedios dispuestos para que el acreedor pueda mitigar los daños y evitar las pérdidas que el incumplimiento pueda causarle, garantizando la conservación del contrato y el futuro cumplimiento de las prestaciones. La Convención le exige al acreedor el cumplimiento de una carga contractual: la conservación de los bienes, pero le otorga un remedio: el derecho a retener las mercaderías hasta ver satisfecho su crédito.

Es factible, en consecuencia, proceder a una reconfiguración del derecho de retención, desde esta óptica inaugurada por la Convención de Viena y que se expresa en el llamado Derecho Uniforme de los Contratos, pero eso deberá ser materia de otra investigación. 


\section{Bibliografía}

\section{Libros}

Abeliuk Manasevich, R., Las Obligaciones, t. iI, 6. ${ }^{\text {a }}$ ed., Legal Publishing Thomson Reuters, 2014 .

Adame Goddard, J., "Las obligaciones del comprador en la compraventa internacional”, Revista de Derecho Privado, n. ${ }^{\circ}$ 9, I 992, 47 I-504.

Albaladejo, M., Derecho Civil II. Derecho de obligaciones, vol. I: La obligación y el contrato en general, Barcelona, José María Bosch, I997.

Bray, S. L., "Announcing remedies", Cornell Law Review, vol. 97, n. I I-I 7, 20 I 2 , $754-755$.

Bacher, K., "Section vi Preservation of the Goods". En Ingeborg Schwenzer (edit.), Schechtriem \& Schwenzer Commentary on the UN Convention on the International Sales of Goods (CISG), 3. ${ }^{\text {rd }}$ ed., Oxford, Oxford University Press, 2010.

Baraona González, J., El retraso en el cumplimiento de las obligaciones, Madrid, Dykinson, I998.

Barrera Graf, J., “Articles 85 to 88 ”. En C. M. Bianca y J. M. Bonell (dirs.), Commentary of the International Sales Law. The I980 Vienna Sales Convention, Milán, Giuffrè, 1987.

Bennett, T., "Article 7 I". En C. M. Bianca y J. M. Bonell (dirs.), Commentary on the International Sales Law. The I98o Vienna Sales Convention, Milán, Giuffrè, I987.

Calvo Caravaca, A., "Disposiciones comunes a las obligaciones del vendedor y del comprador”, en Luis Díez-Picazo y Ponce de León (direc. y coord.), La compraventa internacional de mercaderías. Comentario de la Convención de Viena, Cizur Menor (Navarra), Thomson Civitas, I997, c. v, pp. 70-74.

Caffarena Laporta, J., "Ámbito de aplicación y disposiciones generales", en Luis Díez-Picazo y Ponce de León (direc. y coord.), La compraventa internacional de mercaderias. Comentario de la Convención de Viena, Cizur Menor (Navarra), Thomson Civitas, I997, pp. 59-7 I. 
CANo, J. I., La retención de cosa ajena, Barcelona, Bosch, I990.

Claro Solar, L., Explicaciones de Derecho Civil chileno y comparado, vol. v: De las Obligaciones, Santiago, Editorial Jurídica de Chile, 20 I 3.

Contardo González, J. I., Indemnización y resolución por incumplimiento, Santiago, Thomson Reuters, 2015.

Díez-Picazo, L., Fundamentos de derecho civil patrimonial, t. II: Las relaciones obligatorias, 6. ${ }^{\mathrm{a}}$ ed., Cizur Menor (Navarra), Thomson Civitas, 2008.

D’Ors, J. A. Derecho Privado Romano, Pamplona, Ediciones Universidad de Navarra, I989.

Enderlein, F. y Dietrich M., International Sales Law, Oceania Publicatons, I992.

Enneccerus, L., Tratado de Derecho Civil, t. in, Blas Pérez González y José Alguer (trads.), Barcelona, Bosch, I954.

Echevarría de Rada, T., “En torno al derecho de retención”. En Antonio CaBanillas Sánchez et al. (orgs.), Estudios jurídicos en bomenaje al profesor Luis Diez-Picazo, t. II: Derecho Civil. Derecho de Obligaciones, Madrid, Thomson Civitas, 2003.

Fountoulakis, C., "Section I. Anticipatory breach and instalment contracts". En Ingeborg Schwenzer (edit.), Schlechtriem \& Schwenzer. Commentary on the UN Convention on the International Sale of Goods (CISG), $3 .{ }^{\mathrm{rd}}$ ed., Oxford, Oxford University Press, 2010.

Fueyo Laneri, F., Cumplimiento e incumplimiento de las obligaciones, Santiago, Editorial Jurídica de Chile, I99I.

Galgano, F., Trattato di Diritto Civile, vol. III, 2. a ed., Casa Editrice Dott. Antonio Milani, 20 Io.

Giongi, J., Teoría de las Obligaciones en el derecho moderno, vol. iI, Madrid, Imprenta de la Revista de Legislación, I909.

Hedemann, J. W. Tratado de derecho Civil, vol. in: Derecho de obligaciones, Jaime Santos Briz (trad.), Madrid, Editorial Revista de Derecho Privado, I958. 
JoRdì Capitán, E., Retención posesoria y derecho de retención, Madrid, Dykinson, 2014 .

Larenz, K., Derecho de Obligaciones, t. I, Jaime Santos Briz (trad.), Madrid, Editorial Revista de Derecho Privado, I958.

López de Haro, C., El derecho de retención, Madrid, Reus, I92 I.

Mateo y Villa, Í., El Derecho de retención, Cizur Menor (Navarra), Thomson Reuters Aranzadi, 20I4.

Montes, V., "Conservación de las mercaderías", en Díez-Picazo y Ponce de León, Luis (direc. y coord.), La compraventa internacional de mercaderías. Comentario de la Convención de Viena, Cizur Menor (Navarra), Thomson Civitas, I997, c. v., s. vi., pp. 684-696.

Morales Moreno, A. M., "Conformidad de las mercaderías y pretensiones de terceros”, en Luis Diez-Picazo y Ponce de León (direc. y coord.), La compraventa internacional de mercaderías. Comentario de la Convención de Viena, Cizur Menor (Navarra), Thomson Civitas, I997, pp. 286-355.

Morales Moreno, A. M., La modernización del derecho de obligaciones, Cizur Menor (Navarra), Thomson Civitas, 2006.

Morales Moreno, A. M., "Claves de la modernización del derecho de contratos", en Íñigo De la Maza Gazmuri, Antonio-Manuel Morales Moreno y Álvaro Vidal Olivares, Estudios de Derecho de Contratos. Formación, cumplimiento e incumplimiento, Santiago de Chile, Legal Publishing, 2014, pp. I 5-I 23 .

Ospina Fernández, G., Régimen General de las obligaciones, 8. a ed., Temis, 20 i6.

Pérez Álvarez, M. Á., "La protección del crédito". En Carlos Martínez de Aguirre Aldaz (coord.), Curso de Derecho Civil, vol. II, 4. ${ }^{\text {a }}$ ed., Colex, 20 i 4.

Planiol, M. y Ripert, G., Tratado Elemental de Derecho Civil, t. vi: Contratos de garantía, privilegios e hipotecas, José M. Cajica (trad.), México, Cardenas Editor y Distribuidor, I99I.

SAIDov. D., The Law of damages in international sales. The CISG and other International Instruments, Oxford, Hart Publishing, 2008. 
Sancho Rebullida, F., "Facultad de retención posesoria”. En Francisco de Asís Sancho Rebullida, Estudios de Derecho Civil I, Pamplona, Ediciones Universidad de Navarra, I978.

Schwenzer, I., "Artículo 77". En Ingeborg Schwenzer y Edgardo Muñoz (dirs.), Schlechtriem \& Schwenzer: Comentario sobre la Convención de las Naciones Unidas sobre los contratos de compraventa internacional de mercaderias, Cizur Menor (Navarra), Thomson Reuters Aranzadi, 20 I I.

Soler Presas, A., “Artículo 77”. En Luis Díez-Picazo y Ponce de León (direc. y coord.), La compraventa internacional de mercaderías. Comentario de la Convención de Viena, Cizur Menor (Navarra), Thomson Civitas, I997.

\section{Revistas}

Farnsworth, E. A., "Legal Remedies for Breach of Contract", Columbia Law Review, vol. 70, n. 7 (Nov.), I970, I I 45-I 2 I 6.

Gilbey, S. M., "The Convention on International sales of goods: Anticipatory repudiation provitions and developing countries", International and Comparative Law Quaterly, vol. 38, Issue 3, I989, 475-501.

Mejías Alonzo, C., "La excepción de contrato no cumplido, un análisis de su aplicación en la jurisprudencia nacional reciente y en la doctrina", Revista de Derecho Universidad Católica del Norte, vol. 2 I, n. ${ }^{\circ}$ I, 20 I4, I I I-I 56.

Oviedo Albán, J., "Los principios generales en la Convención de Naciones Unidas sobre compraventa internacional de mercaderías", Boletín Mexicano de Derecho Comparado, vol. 47, n. ${ }^{\circ}$ I4I, 2014,987 -1020.

Perales Viscasillas, M., "El contrato de compraventa internacional de mercaderías. (Convención de Viena de I980)", 200I; disponible en http://www. cisg.law.pace.edu/cisg/biblio/perales I.html; consultado: 28 de junio de 20 I6.

Pizarro Wilson, C., "El derecho de retención. Una garantía bajo sospecha", Revista Ius et Praxis, vol. I 5, n. ${ }^{\circ}$ I, 2009, 339-352.

Rodríguez Fernández, M., "El deber de mitigar el daño en la Convención de Viena de i980 sobre compraventa internacional de mercaderías: una breve aproximación al tema”, Revista e-Mercatoria, vol. 6, n. ${ }^{2}$ 2, 2007. 
Ternera Barrios, F. y Mantilla Espinosa, F., "Posesión y retención: ¿hechos, derechos o quimeras?", Revista Chilena de Derecho Privado, Fundación Fernando Fueyo, diciembre 2010 , p. I 25.

Vidal Olivares, Á., "El incumplimiento contractual y los remedios de que dispone el acreedor en la compraventa internacional", Revista Chilena de Derecho, vol. 33, n. $^{\circ} 3,2006,439-477$.

\section{Legislaciones}

Convención de la Naciones Unidas sobre los contratos de compraventa internacional de mercaderías, Naciones Unidas, Nueva York, 20 I I.

United Nations Convention of Contracts for International Sales of Goods, New York, 20Io; disponible en http://www.uncitral.org/pdf/english/texts/sales/ cisg/VI 056997-CISG-e-book.pdf; consultado: 25 de abril de 20 i6.

United States of America Uniform Commercial Code, by The American Law Institute and the National Conference of Commissioners on Uniform State Laws; disponible en https://www.law.cornell.edu/ucc; consultado: 25 de julio de 2016.

\section{Casos}

U.S. Supreme Court Marbury v. Madison, 5 U.S. I Cranch I 37 I 37 (I803); disponible en: https://supreme.justia.com/cases/federal/us/5/I37/

ICC International Court of Arbitration case no. 753 I de I994, Austria vs. China; disponible en http://cisgw3.law.pace.edu/cases/94753 rir.html

U.S. District Court, Northern District of New York Delchi v. Rotorex 9 September i994. Caso n. ${ }^{\circ} 88-\mathrm{CV}$-1078 de i994, Italia vs. EeuU; disponible en http://cisgw3.law.pace.edu/cases/940909ur.html

Tribunal cantonal de Vaud, i 7 May i994, Caso n. ${ }^{\circ}$ or 93 I 308 de I994, Suiza vs. Alemania; disponible en http://cisgw3.law.pace.edu/cases/9405 I 7s r.html

Tribunal of International Commercial Arbitration at the Russian Federation Chamber of Commerce and Industry, caso n. ${ }^{\circ}$ 200/I 994 of 25 April I995, Suiza vs. Rusia; disponible en http://cisgw3.law.pace.edu/cases/950425rI. html 
Supreme Court of British Columbia (Mansonville v. Kurtz), Caso n. ${ }^{\circ}$ C993594, 2 I de agosto de 2003, Canadá vs. Austria; disponible en http://cisgw3.law. pace.edu/cases/o3o82 Ic4.html

Appellate Court Antwerp (GmbH Lothringer Gunther Grosshandelsgesellschaft für Bauelemente und Holzwerkstoffe $v$. NV Fepco International), caso n. ${ }^{\circ} 2002 / A R / 2087,24$ de abril de 2006, Bélgica vs. Alemania; disponible en http://cisgw3.law.pace.edu/cases/o6o424br.html

Tribunale di Forli (Mitias v. Solidea S.r.l.), caso n. ${ }^{\circ} 2280 / 2007$, Italia, I I diciembre de 2008 , Eslovenia vs. Italia; disponible en http://cisgw3.law.pace.edu/ cases/o8 I 2 I riz.html

China International Economic and Trade Arbitration Commission, caso n. ${ }^{\circ}$ CISG/2005/o8, China, 24 de febrero de 2005, China vs. Rusia; disponible en http://cisgw3.law.pace.edu/cases/0502 24c2.html

Audiencia Provincial de Cantabria, sección 2. a , caso n. ${ }^{\circ}$ 45/2003 del 2004, España, 5 de febrero de 2004; disponible en http://cisgw3.law.pace.edu/ cases/040205s4.html

Lower Court Frankfurt, caso n. ${ }^{\circ}{ }_{32} \mathrm{Cio74}_{900-4 I}$ de i99 I, Alemania, 3 I de enero de I99I, Italia vs. Alemania; disponible en http://cisgw3.law.pace.edu/ cases/9ior 3 Igr.html 